\title{
Factors associated with a positive intake of folic acid in the periconceptional period among Korean women
}

\author{
Min-Hyoung Kim ${ }^{1}$, Jung-Yeol Han ${ }^{1, *}$, Yeon-Jin Cho ${ }^{1}$, Hyun-Kyong Ahn ${ }^{1}$, Joo-Oh Kim ${ }^{1}$, \\ Hyun-Mee Ryu' ${ }^{1}$, Moon-Young Kim ${ }^{1}$, Jae-Hyug Yang ${ }^{1}$ and Alejandro A Nava-Ocampo ${ }^{2}$ \\ ${ }^{1}$ Korean Motherisk Program, Department of Obstetrics \& Gynecology, Cheil Hospital and Women's Healthcare \\ Center, 1-9 Mookjung-Dong, Chung-Gu, Seoul, South Korea: ${ }^{2}$ Division of Clinical Pharmacology \& Toxicology, \\ Hospital for Sick Children, Toronto, Ontario, Canada
}

Submitted 2 July 2007: Accepted 20 February 2008: First published online 24 December 2008

\begin{abstract}
Objective: We aimed to investigate the factors associated with a positive intake of folic acid (FA) during the periconceptional period among Korean women.

Design: In a cross-sectional study of demographic, obstetric and socio-economic data, history of periconceptional intake of FA and awareness of the benefits of FA supplementation in pregnancy were obtained and analysed using the $\chi^{2}$ test, followed by multiple logistic regression analysis.

Setting: The Maternity School, Cheil General Hospital and Women's Healthcare Center, Seoul, South Korea, between October 2005 and March 2006.

Subjects: In total 1313 pregnant women participating in a two-day training course available every month.

Results: After excluding subjects with incomplete or inconsistent data, there were 1277 women included in the analysis. Participants were aged 29.4 (SD 2.9) years and had a mean gestational age of $27 \cdot 9$ (SD 7.1) weeks. Only $131(10 \cdot 3 \%)$ women took FA during the periconceptional period. According to multiple logistic regression analyses, the adjusted OR for FA supplementation was 1.79 (95\% CI $1 \cdot 10,2 \cdot 91)$ in women who had previous spontaneous abortions, $4 \cdot 10$ (95\% CI $2 \cdot 43,6 \cdot 78)$ in women who planned their pregnancy and $6 \cdot 63(95 \%$ CI $2 \cdot 08,21 \cdot 12)$ in those who were aware of the protective effects of FA.

Conclusions: Periconceptional intake of FA was more likely among Korean women with a history of previous spontaneous abortion, who planned their pregnancy or who were aware of the protective effects of FA during pregnancy. However, the proportion of women who took FA in the periconceptional period was low.
\end{abstract}

\section{Keywords Folic acid Neural tube defects Periconceptional care}

Neurulation is the fundamental embryonic process that leads to the development of the neural tube in two phases $^{(1)}$. The first phase occurs between the third and fourth developmental week (primary neurulation) and leads to the formation of the brain and most of the spinal cord. Secondary neurulation occurs between the fifth and sixth developmental week and creates the lowest portion of the spinal cord including most of the sacral and all of the coccygeal regions. A neurulation defect results in the formation of neural tube defects (NTD). A multi-centre study monitoring all birth defects in Korea reported approximately 3.5 pregnancies per 10000 births to be affected by $\mathrm{NTD}^{(2)}$. On the other hand, it has been estimated that $50-70 \%$ of NTD could be prevented by a daily intake of at least $400 \mu \mathrm{g}$ of folic acid (FA) in the periconceptional period $^{(3)}$; the highest efficacy of FA is expected to occur at a daily dose level of $5 \mathrm{mg}^{(4)}$. Unfortunately, approximately
$50 \%$ of all pregnancies in Korea are unintended ${ }^{(5)}$, jeopardizing our efforts to promote FA supplementation during the periconceptional period.

Because of the importance of establishing successful public programmes to promote FA supplementation among women of childbearing age, we aimed to investigate which factors are associated with a positive intake of FA in the periconceptional period among Korean women.

\section{Methods}

The study was approved by the Institutional Research Board at the Cheil General Hospital and Women's Healthcare Center, Seoul, South Korea, and voluntary consent was obtained from all participants. Within a 6-month period, from October 2005 to March 2006, a questionnaire was given to 1313 pregnant women who 
were participating in a two-day training course at the maternity school of the hospital. The course was available every month and provided information for pregnant women on the prenatal, birth and postpartum periods as well as on breast-feeding benefits. The following information was obtained from the participants: maternal and gestational age, obstetric history (gravidity, parity, number of vaginal deliveries, number of previous abortions), employment status, educational level and household monthly income level. The participants also provided information on whether their current pregnancy was planned, whether they took FA supplementation in the periconceptional period, and whether they were aware of the prevention of NTD by periconceptional supplementation of FA. If participants had a positive history of FA intake, they were also asked to provide the dose according to the following three categories: unknown dose, $400 \mu \mathrm{g} / \mathrm{d}$ or $>400 \mu \mathrm{g} / \mathrm{d}$.

For purposes of the present study, the following variables were classified into two categories: age as $<35$ years and $\geq 35$ years; number of previous spontaneous abortions as 0 and $\geq 1$; employment status as employed and unemployed; educational level as high school or less and college or higher; and household monthly income level as <\$US 2000 and $\geq$ \$US 2000. The latter was classified by considering that lower economic class in Korea has an average monthly income of <\$US 2000 (\$US 1 was equivalent to approximately 1000 Won at the time of the study). In addition, the time elapsed from 3 months before the estimated date of conception to 4 weeks postconception was considered as the periconceptional period. Based on the approximate time at which the first phase of neurulation is completed ${ }^{(1)}$, we limited the periconceptional period to 4 weeks postconception.

Demographic, obstetric and socio-economic data were compared between participants with positive and negative supplementation of FA in the periconceptional period by the $\chi^{2}$ test. Those characteristics identified as statistically different between groups $(P<0 \cdot 05)$ were subsequently included in multivariate logistic regression analyses in order to obtain the corresponding adjusted odds ratio and 95\% confidence interval. The statistical analyses were performed using the Statistical Package for the Social Sciences statistical software package version 10.07 (SPSS Inc., Chicago, IL, USA); all statistical tests were done with $\alpha$ of 0.05 by two-tailed tests.

\section{Results}

After excluding subjects with incomplete or inconsistent data, $1277(97 \cdot 3 \%)$ women were included in the analysis. Included participants were aged $29 \cdot 4$ (SD 2.9) years and had a mean gestational age of $27 \cdot 9(\mathrm{SD} 7 \cdot 1)$ weeks. There were $131(10 \cdot 3 \%)$ women who took FA during the periconceptional period. Of them, $84.0 \%$ had an education level of college or higher, $\mathbf{7 4} \cdot 8 \%$ were primigravidas, $19 \cdot 1 \%$ had $\geq 1$ previous spontaneous abortion and in $86.3 \%$ the pregnancy was planned. The dose of FA was unknown in ninety-eight participants $(74 \cdot 8 \%), 400 \mu \mathrm{g} / \mathrm{d}$ in 30 participants $(22 \cdot 9 \%)$ and $>400 \mu \mathrm{g} / \mathrm{d}$ in three participants $(2 \cdot 3 \%)$.

The percentage of women with previous spontaneous abortions or who had planned their pregnancy was higher in the group who took FA in the periconceptional period than in the group who did not (Table 1). According to multiple logistic regression analyses, women who had $\geq 1$ previous spontaneous abortions, planned their pregnancy and were aware of the protective effects of FA were more likely to take FA during the periconceptional period. The adjusted OR were 1.79 (95\% CI $1 \cdot 10,2 \cdot 91 ; P=0 \cdot 02), 4 \cdot 10$ (95\% CI 2.43, 6.78; $P<0.001)$ and $6.63(95 \%$ CI $2 \cdot 08,21 \cdot 12 ; P=0.001)$, respectively (Table 2 ).

\section{Discussion}

The present study found that only a small percentage $(10 \cdot 3 \%)$ of Korean women took FA supplementation during the periconceptional period. This rate is considerably lower than the $20 \cdot 3 \%$ reported previously in Qatar $^{(6)}, 25 \%$ in Canada $^{(7)}, 32 \%$ in the $\mathrm{USA}^{(8)}$ and $45 \cdot 5 \%$

Table 1 Demographic, socio-economic and clinical characteristics: pregnant Korean women (n 1277), October 2005-March 2006

\begin{tabular}{|c|c|c|c|c|c|c|}
\hline & \multicolumn{4}{|c|}{ Periconceptional intake of folic acid } & \multirow[b]{3}{*}{$\chi^{2}$} & \multirow[b]{3}{*}{$P$} \\
\hline & \multicolumn{2}{|c|}{ Yes (n 131) } & \multicolumn{2}{|c|}{ No (n 1146) } & & \\
\hline & $n$ & $\%$ & $n$ & $\%$ & & \\
\hline Age $\geq 35$ years & 7 & $5 \cdot 3$ & 51 & $4 \cdot 5$ & $0 \cdot 22$ & 0.64 \\
\hline Primigravida & 98 & $74 \cdot 8$ & 897 & $78 \cdot 3$ & $0 \cdot 81$ & $0 \cdot 37$ \\
\hline Previous spontaneous abortions $\geq 1$ & 25 & $19 \cdot 1$ & 126 & $11 \cdot 0$ & $7 \cdot 38$ & 0.007 \\
\hline Planned current pregnancy & 113 & $86 \cdot 3$ & 686 & $59 \cdot 9$ & $35 \cdot 00$ & $<0.001$ \\
\hline Aware of preventive effects of folic acid & 128 & $97 \cdot 7$ & 983 & $85 \cdot 8$ & $14 \cdot 80$ & $<0.001$ \\
\hline Employment status* & 103 & $78 \cdot 6$ & 881 & $76 \cdot 9$ & 0.19 & 0.66 \\
\hline Education level college or higher & 110 & $84 \cdot 0$ & 962 & 83.9 & 0.00 & 0.99 \\
\hline Household monthly income $\geq \$$ US $2000 \dagger$ & 98 & $74 \cdot 8$ & 791 & $69 \cdot 0$ & $1 \cdot 86$ & $0 \cdot 17$ \\
\hline
\end{tabular}

*Employment status at the time of periconceptional period.

t\$US $1=1000$ Won. 
Table 2 Factors associated with periconceptional intake of folic acid: pregnant Korean women, October 2005-March 2006

\begin{tabular}{lccr}
\hline Variable & Adjusted OR & $95 \% \mathrm{Cl}$ & \multicolumn{1}{c}{$P$} \\
\hline Previous spontaneous abortions $\geq 1$ & $1 \cdot 79$ & $1 \cdot 10,2 \cdot 91$ & $0 \cdot 02$ \\
Planned current pregnancy & $4 \cdot 10$ & $2 \cdot 43,6 \cdot 78$ & $<0 \cdot 001$ \\
Aware of preventive effects of folic acid & $6 \cdot 63$ & $2 \cdot 08,21 \cdot 12$ & $0 \cdot 001$ \\
\hline
\end{tabular}

The results were obtained by multiple logistic regression analyses and included the three variables that resulted as statistically significant in the comparisons between women who took folic acid in the periconceptional period and those who did not.

in the United Arab Emirates ${ }^{(9)}$. Over the past decade the birth rate in Korea has decreased markedly, to as low as 1.08 per couple ${ }^{(10)}$. However, the rate of planned pregnancies remains low. For example, only $50 \%$ of women receiving teratogen-risk counselling services at the Korean Motherisk Program reported a planned pregnancy ${ }^{(5)}$, and although the percentage was higher in the present study (63.5\%), it implies that at least one third of all pregnancies are still unplanned. In the present study, the percentage of planned pregnancies was significantly higher among women who took FA in the periconceptional period than among non-takers of FA. However, the percentage of planned pregnancies was at least five times more than the overall percentage of women who took FA, suggesting that other factors may also affect the periconceptional supplementation of FA.

It is known that highly educated women know more about FA and take it more often in the periconceptional period and first trimester of pregnancy ${ }^{(6,11)}$. In the present study, the percentage of women who were employed, had an education level of college or higher or had a household monthly income level $\geq$ \$US 2000 did not differ between FA takers and non-takers. On the other hand, a planned pregnancy, the adverse experience of previous abortions and awareness of the benefits of $\mathrm{FA}$ in pregnancy were associated with a significantly higher intake of FA during the periconceptional period. However, we were not able to clarify whether in a real-time situation these three factors would independently favour FA supplementation during the periconceptional period. In a previous study, variations in the attitude of women to take FA during the periconceptional period were secondary to the variable knowledge of its benefits among their obstetricians ${ }^{(12)}$. However, the main source of information on the benefits of FA in early pregnancy appears to be the mass media ${ }^{(13)}$. This knowledge will be critical in providing public strategies and national campaigns to increase folate awareness among women of childbearing age. On the other hand, the number of unplanned pregnancies remains considerably elevated ${ }^{(5)}$, limiting the efficacy of public education campaigns to encourage the periconceptional use of FA supplements.

The present study was performed among pregnant women at a mean gestational age of 28 weeks; women who had miscarriages or terminated their pregnancies were not included and therefore their attitude towards intake of $\mathrm{FA}$ in the periconceptional period was not taken into account. In addition, we cannot rule out the recall bias at this advanced gestational age concerning the periconceptional intake of FA among participants. The dose of FA was not evaluated in detail, and therefore some women who took only a few doses during their first weeks of pregnancy were classified as subjects with positive FA supplementation. Finally, for purposes of the analyses, the study variables were categorized a priori, limiting evaluation of the effect of certain variables, e.g. age, on FA supplementation in a wider range of possibilities.

There is still an ongoing debate on the pros and cons of mandatory FA fortification ${ }^{(14,15)}$; among the cons, FA has been associated with potential cancer promotion as well as with a decrease in plasma homocysteine levels. In addition, FA fortification has been found to be a cause of masking vitamin $\mathrm{B}_{12}$ deficiency, particularly in the elderly population $^{(16)}$. However, diet by itself does not appear to provide pregnant women with sufficient amounts of folate to prevent major birth defects. For example, in Norway, the country with the highest rate of facial clefts in Europe, the fortification of foods with FA has not been allowed $^{(17)}$. In contrast, flour and other grain products are being fortified at a minimum level of $0.14 \mathrm{mg} \mathrm{FA} / 100 \mathrm{~g}$ cereal grain in Canada and the USA and a decline in NTD was observed as a result of that fortification ${ }^{(18,19)}$. However, the fortification level should be enough to provide a daily intake of 0.6 to $0.8 \mathrm{mg} \mathrm{FA}$ in order to attain the highest benefits ${ }^{(20)}$. In contrast, there is no independent gold standard or reference method for unequivocal characterization of vitamin $\mathrm{B}_{12}$ deficiency, nor an agreement on how to treat or when and how to monitor the effects of treatment available ${ }^{(16)}$. Although deficiency of vitamin $\mathrm{B}_{12}$ in an elderly subpopulation cannot be minimized, the current analysis of risks and benefits is in favour of FA fortification, especially in a population where a very low percentage of pregnant women receive FA supplementation in the periconceptional period and most of women who received FA ignore the dose.

In summary, Korean women undergoing a planned pregnancy, who had previous spontaneous abortions and who were aware of the preventive effects of FA were more likely to take FA during the periconceptional period than those who did not. However, despite its proven efficacy for preventing congenital malformations, intentional intake of $\mathrm{FA}$ at the periconceptional period occurred in only approximately $10 \%$ of women. 


\section{Acknowledgements}

Author contributions: J.-Y.H. conceived the idea and study design, and coordinated the study. Y.-J.C. collected the information in electronic databases. A.A.N.-O. participated in the study design. H.-K.A. and J.-O.K. performed the statistical analyses. All the authors participated in drafting the manuscript, discussing the results, and preparing, reviewing and correcting the manuscript.

Acknowledgements: The authors are indebted to pregnant women who participated in the study during the maternity course at Cheil Hospital and Healthcare Center, Kwandong University College of Medicine, Seoul, South Korea.

We have no conflicts of interest to declare.

\section{References}

1. Kibar Z, Capra V \& Gros P (2007) Toward understanding the genetic basis of neural tube defects. Clin Genet $\mathbf{7 1}$, 295-310.

2. Yang JH, Kim YJ, Chung JH et al. (2004) A multi-center study for birth defect monitoring system in Korea.J Korean Med Sci 19, 509-513.

3. Johnston RB Jr (1997) Folic acid: new dimensions of an old friendship. Adv Pediatr 44, 231-261.

4. Wald NJ, Law MR, Morris JK \& Wald DS (2001) Quantifying the effect of folic acid. Lancet 358, 2069-2073.

5. Han JY, Nava-Ocampo AA \& Koren G (2005) Unintended pregnancies and exposure to potential human teratogens. Birth Defects Res A Clin Mol Teratol 73, 245-248.

6. Bener A, Al Maadid MG, Al-Bast DA \& Al-Marri S (2006) Maternal knowledge, attitude and practice of folic acid intake among Arabian Qatari women. Reprod Toxicol 21, 21-25.

7. Morin P, De Wals P, St-Cyr-Tribble D, Niyonsenga T \& Payette H (2002) Pregnancy planning: a determinant of folic acid supplements use for the primary prevention of neural tube defects. Can J Public Health 93, 259-263.
8. Centers for Disease Control and Prevention (1999) Knowledge and use of folic acid by women of childbearing age United States, 1995 and 1998. MMWR Morb Mortal Wkly Rep 48, 325-327.

9. Abdulrazzaq YM, Al-Gazali LI, Bener A, Hossein M, Verghese M, Dawodu A \& Padmanabhan R (2003) Folic acid awareness and intake survey in the United Arab Emirates. Reprod Toxicol 17, 171-176.

10. National Statistical Office of Korea (2006) http://www. kosis.kr/OLAP/Analysis/stat_OLAP.jsp?tbl_id=DT_1B8000A\& org_id=101\&vwcd=MT_E_TITLE\&path=\&oper_YN=Y\&item= \&keyword=\&lang_mode $=$ engelist_id $=\mathrm{A} 2 \&$ olapYN $=\mathrm{N}$ (accessed May 2007).

11. Daltveit AK, Vollset SE, Lande B \& Øien H (2004) Changes in knowledge and attitudes of folate, and use of dietary supplements among women of reproductive age in Norway 1998-2000. Scand J Public Health 32, 264-271.

12. Power ML, Holzman GB \& Schulkin J (2000) Knowledge and clinical practice regarding folic acid among obstetrician-gynecologists. Obstet Gynecol 95, 895-898.

13. Bekkers RLM \& Eskes TKAB (1999) Periconceptional folic acid intake in Nijmegen, Netherlands. Lancet 353, 292.

14. Wald NJ \& Oakley GP (2007) Should folic acid fortification be mandatory? Yes. BMJ 334, 1252.

15. Hubner RA, Houlston RD \& Muir KR (2007) Should folic acid fortification be mandatory? No. BMJ 334, 1253.

16. Cuskelly GJ, Mooney KM \& Young IS (2007) Folate and vitamin $\mathrm{B}_{12}$ : friendly or enemy nutrients for the elderly. Proc Nutr Soc 66, 548-558.

17. Mossey PA \& Little J (2002) Epidemiology of oral clefts: an international perspective. In Cleft Lip and Palate: From Origin To Treatment, pp. 170-192 [DE Wyszynski, editor]. Oxford: Oxford University Press.

18. Ray JG, Meier C, Vermeulen MJ, Boss S, Wyatt PR \& Cole DEC (2002) Association of neural tube defects and folic acid food fortification in Canada. Lancet 360, 2047-2048.

19. De Wals P, Tairou F, van Allen MI et al. (2007) Reduction in neural-tube defects after folic acid fortification in Canada. $N$ Engl J Med 357, 135-142.

20. Wald NJ (2004) Folic acid and the prevention of neuraltube defects. N Engl J Med 350, 101-103. 